\title{
Pengaruh Shalat Dhuha terhadap Pembentukan Karakter Siswa Di MIN 1 Kendari
}

\author{
Desriyani $^{1}$, Marlina ${ }^{2}$, \\ 1 Institut Agama Islam Negeri Kendari \\ 2 Institut Agama Islam Negeri Kendari, Indonesia. E-mail: marlinagazali65@gmail.com
}

\begin{tabular}{|c|c|}
\hline Articel info & Abstract \\
\hline $\begin{array}{l}\text { Artikel history: } \\
\text { Received: } 18 \text { April } 2020 \\
\text { Revised: } 19 \text { April } 2019 \\
\text { Accepted: } 19 \text { April } 2020\end{array}$ & $\begin{array}{l}\text { The objective of this research was to asses the effect of Sholat Dhuha to } \\
\text { student's character building in Islamic Elementary School } 1 \text { Kendari. This } \\
\text { study is a mix method with } 98 \text { students as sample gained through stratified } \\
\text { random sampling. The data were collected throught interview, } \\
\text { documentation, and questionnaire then were analysed by using product } \\
\text { moment correlation and simpe linear regresi test. The study showed that the } \\
\text { practice of Sholat Dhuha in Elementary School } 1 \text { Kendari was fully } \\
\text { implemented with } 86 \text { to } 100 \text { average score. The building of student's } \\
\text { character was trained throught the practice of well speech, disciplinary, and } \\
\text { and honesty with average score } 86-100 \text {, indicating that the students are well- } \\
\text { behaved and there is a positive effect of sholat dhuha to character building } \\
\text { of the students. However, based on coefficient of determination the effect } \\
\text { made was only } 30 \% \text {, other factors were not studied. }\end{array}$ \\
\hline
\end{tabular}

\section{Informasi Artikel}

Riwayat Artikel:

Diterima: 18 April 2020

Direvisi: 19 April 2020

Accepted: 19 April 2020
Abstrak

Penelitian ini bertujuan untuk mengetahuti apakah ada pengaruh shalat dhuha terhadap pembentukan karakter siswa di MIN 1 Kendari. Penelitian ini adalah penelitian kuantitatif dan kualitatif (mix methods) dengan sampel dalam penilitian ini 98 orang dengan menggunakan tehnik stratified random sampling. Analisis data yang digunakan adalah uji korelasi product moment dan uji regresi linear sederhana. Hasil penelitian menunjukan bahwa: Pelaksanan shalat dhuha di MIN 1 kendari memperoleh hasil di atas rata-rata yaitu 86-100, sehingga dapat dikatakan bahwa sebagian besar siswa melaksanakan shalat dhuha berada pada kategori sangat baik. Pembentukan karakter siswa di MIN 1 Kendari dimulai dari tutur bahasanya, kedisiplinan dan kejujuran siswa dari skor perolehan 86-100, sehingga dapat dikatakan bahwa karakter siswa di MIN 1 Kendari termasuk dalam kategori sangat baik dan terdapat pengaruh positif dan signifikansi shalat dhuha terhadap pembentukan karakter siswa dengan $r_{\text {hitwg }}$ lebih besar dari pada $r_{\text {tabel }}$ $(0.55 \geq 0.1671)$ dan uji $\mathrm{t}$ signifikansi $\mathrm{t}_{\text {hitung }} \geq \mathrm{t}_{\text {tabel }}(6,44$ $\geq 1,66055)$ maka $\mathrm{H}_{\mathrm{I}}$ diterima dan $\mathrm{H}_{0}$ ditolak artinya terdapat pengaruh yang positif dan signifikan shalat dhuha terhadap pembentukan karakter siswa di MIN 1 Kendari dengan demikian hipotesis awal yang menyatakan bahwa pengaruh shalat dhuha terhadap pembentukan karakter siswa dapat 
diterima. Hasil analisis koefisien deteriminasi (KD) pengaruh shalat dhuha terhadap pembentukan karakter siswa sebesar $30 \%$ dan $70 \%$ dipengaruhi faktor lain yang tidak diteliti dalam penelitian ini.

\section{PENDAHULUAN}

Pendidikan merupakan faktor yang sangat berpengaruh dalam pembangunan bangsa yang lebih baik. Pendidikan sangat penting dalam pembentukan watak siswa dan menjadi warga Negara yang baik serta dapat mengembangkan karakter. Kenyataan sekarang ini bangsa Indonesia digambarkan sebagai bangsa yang mengalami penurunan kualitas karakter pelajarnya, mulai dari masalah tawuran antar pelajar, kekerasan dan kurangnya sifat saling tolong menolong. Permasalahan ini memicu pemerintah Indonesia harus memperbaiki hal tersebut, yang dimulai dari penanaman nilai-nilai agama, norma bangsa Indonesia terutama dalam lembaga pendidikan.

Usaha pemerintah dalam memperbaiki waktak dan karakter bangsa sangat jelas tertera pada fungsi dari pendidikan itu sendiri yaitu mengembangkan kemampuan dan membentuk watak serta perbedaan bangsa yang bermartabat dalam rangka mencedaskan kehidupan bangsa, bertujuan untuk berkembangnya potensi peserta didik agar menjadi manusia yang beriman dan bertakwa kepada Tuhan yang Maha Esa, berakhlak mulia, sehat berilmu cakap, kreatif, mandiri dan menjadi warga Negara yang demokratis serta bertanggung jawab (UU No.20 tahun 2003.)

Namun kenyataan di lapangan menunjukkan bahwa misi pembentukan karakter bangsa belum sepenuhnya tercapai. Berdasarkan hasil pengamatan peneliti pada beberapa sekolah dasar di kota kendari menunjukkan bahwa karakter siswa sekolah dasar masih jauh dari apa yang diharapakan. Banyak siswa di sekolah kurang mematuhi instruksi guru saat proses belajar mengajar, sering berkelahi sama temannya, sering berkata kasar pada orang-orang di sekitarnya dan sering terlambat kesekolah.

Berdasarkan hasil wawancara peneliti dengan beberapa guru di MIN Kendari terungkap bahwa penanaman rasa keimanan dan pembentukan karakter siswa MIN 1 Kendari dilakukan dengan pembiasaan sholat dhuha. Shalat dhuha dilakukan sebelum kegiatan proses belajar mengajar dimulai. Biasanya sholat sunnat ini dilaksankan secara berjamaah oleh siswa di MIN satu Kendari pada hari jumat, selain hari itu siswa melaksanakan sholat dhuha di kelas masing-masing. Bila salah satu dari siswa tidak melaksanakan akan diberi sanksi berupa tugas hapalan surat-surat pendek.

Shalat dhuha adalah shalat sunah yang dikerjakan pada waktu matahari naik sekitar satu tembok atau sekitar pukul 07.00 WIB hingga tergelincirnya matahari menjelang waktu shalat zhuhur. Walaupun shalat dhuha termasuk macam-macam shalat sunah, tetapi shalat dhuha temasuk shalat yang dianjurkan oleh Rasulullah saw kepada umatnya yang sebagaimana wasiat Rasulullah kepada Abu Hurairah dia berkata," kekasihku (Rasulullah SAW) telah berwasiat kepadaku dengan tiga perkara yang aku tidak boleh meninggalkannya, baik ketika menetap atau dalam perjalanan, yaitu dua rakaat shalat dhuha, berpuasa tiga hari setiap bulan dan agar aku tidak tidur kecuali setelah melakukan shalat witir. (Tirmidzi"' 2005)

Pengamalan ajaran agama Islam Berupa pembiasaan sholat dhuha di lingkungan sekolah diharapkan dapat menanamkan nilai-nilai yang religious dalam jiwa peserta didik sehingga dapat membentuk karakter peseta didik. Lembaga pendidikan di MIN 1 Kendari telah menjadikan sebuah teori pelajaran kedalam bentuk praktet keseharian yaitu memasukan kedalam program rutin sekolah. Tujuannya untuk melatih peserta didik untuk mengembangkan kepribadian mulia serta nilai religious dalam lingkungan sekolah, dimana mereka dilatih dan dididik untuk mengembangkan keterampilan dan mental mereka kearah yang lebih baik. Sehingga lembaga tersebut dapat menciptakan out put yang berkarakter yang baik. Berdasarkan pemaparan tersebut peneliti terdorong untuk mengetahui adakah pengaruh dari pelaksanaan shalat dhuha terhadap pembentukan karakter siswa di MIN 1 Kendari

\section{METODE}

Penelitian dilakukan dengan pendekataan kuantitatif dan kualitatif (mix methods). Penelitian ini akan mendeskipsikan tentang pengaruh shalat dhuha terhadap pembentukan karakter siswa. Pembahasan 
hasil penelitian ini akan diuraikan dengan pola analisis statistik deskritif, dimana data yang berupa angka ditabulasikan dalam bentuk tabel distribusi frekuensi dan presentase untuk tujuan memberikan gambaran atau deskripsi tentang data yang ada yang ada sebagai hasil penelitian. Mix methods adalah metode penelitian dengan mengkombinasikan antara dua metode penelitian sekaligus, kuantitatif dan kualitatif dalam suatu kegiatan penelitian, sehingga akan diperoleh data yang komperhensif valid, reliable dan objektif. (Sugiyono.,2017)

Populasi adalah wilayah generalisir yang terdiri atas objek atau subjek yang mempuyai kualitas dan krakteristik tertentu yang ditetapkan oleh peneliti untuk dipelajari kemudian ditarik kesimpulannya. (Sugiyono.,2014). Populasi dalam penelitian ini adalah siswa di MIN 1 Kendari kelas 4 dan 5 yang berjumlah 130 orang. Dengan sampel penelitian sebesar 98 orang dengan menggunakan rumus taro dan slovin (Suyanto., 2017). Tehnik pengambilan sampel menggunakan stratified random sampling dengan dengan cara undian dan tehnik pengumpalan data dilakukan dengan angket, wawancara dan dokumentasi. Tehnik analisis data menggunakan uji regresi untuk mengetahui ada tidak pengaruh shalat dhuha terhadap pembentukan karakter dan untuk mengetahui berapa sumbangsi shalat dhuha terhadap pembentukan karakter mengunakan rumus koefisien deteriminasi.

\section{HASIL PENELITIAN}

MIN 1 Kendari merupakan salah satu sekolah di kota Kendari yang telah menerapkan shalat dhuha sebelum pembelajaran dimulai, kegiatan shalat dhuha ini dilaksanakan semenjak tahun 2015 di MIN 1 Kendari sejak dipimpin oleh ibu Sitti Juhasni.

\section{Pelaksanaan Shalat Dhuha di MIN 1 Kendari}

Shalat dhuha adalah shalat sunah yang dilakukan pada pagi hari antara pukul 07.00 sampai dengan pukul 10.00 waktu setempat. Jumlah rakaat shalat dhuha minimal dua rakaat dan maksimal dua belas rakaat dengan salam setiap dua rakaat. (Aziz., 2008), oleh karena itu shalat di MIN 1Kendari dilaksanakan secara berjamaah pada hari jumat sebelum pembelajaran dimuali dan hari hari biasanya dilaksanakan dimasing-masing rungan,shalat dhuha dilaksanakan pada pukul 6.45, biasanya sebelum melaksanakan shalat dhuha siswa menghafal surah-surah pendek terutama jus 30 dan setelah melaksanakan shalat dhuha dilajutkan dengan membaca surah yasin dan dan menghafal ayat-ayat pilihan seperti ayat kursi dan surah al baqarah ayat 284-287. Pelaksanaan shalat dhuha ini tujunnya untuk membiasakan shalat dhuha kepada siswa dan membentuk karakter siswa kegiatan ini sangat berperan penting dalam membentuk karakter siswa karena dengan kegiatan pelaksaanaan shalat dhuha siswa terbiasa melaksanakan shalat dhuha tampa harus diperintah oleh guru. Aturan sekolah untuk kegiatan pelaksanaan shalat dhuha siswa yang tidak mengikuti atau terlambat melaksakan shalat dhuha akan dikenakan denda atau hukuman yang berupa menghafal surah-surah pendek, dan membayar uang dua ribu dan melaksanakan shalat dhuha sendiri, jika siswa tidak bisa menghafal surah-surah pendek maka harus menhafal asmaul husna, aturan sekolah merupkan bentuk pembinaan yang dilakukan oleh sekolah dalam membentuk karakter siswa agar lebih menjadi baik serta memiliki kepedulian terhadap kedisiplinannya, pembinaan di MIN 1 Kendari tidak hanya penegakan aturan tetapi melaui himbauan-himbauan atau memperingati siswa yang diberikan pada saat apel pagi sebelum siswa memulai kegiatan pembelajaran.

Berdasarkan hasil analisis data dan pengujian hipotesis, dapat diuraikan hasil penelitian sebagai berikut. Secara deskriptif, hasil analisis deskriptif menunjukan bahwa skor shalat dhuha siswa di MIN 1 Kendari dengan skor maksimum $=21$, skor minimum $=11$, skor median $=18$, skor modus $=$ 18 , skor mean $=17,92857$ dan skor star deviasi $=1,895464$. Maka untuk mempermudah memahami data hasil olahan instrument variabel $X$ yang diperoleh, dapat disajikan data instrument variabel $X$ pelaksanaan shalat dhuha melalui tampilan diagram sebagai berikut: 


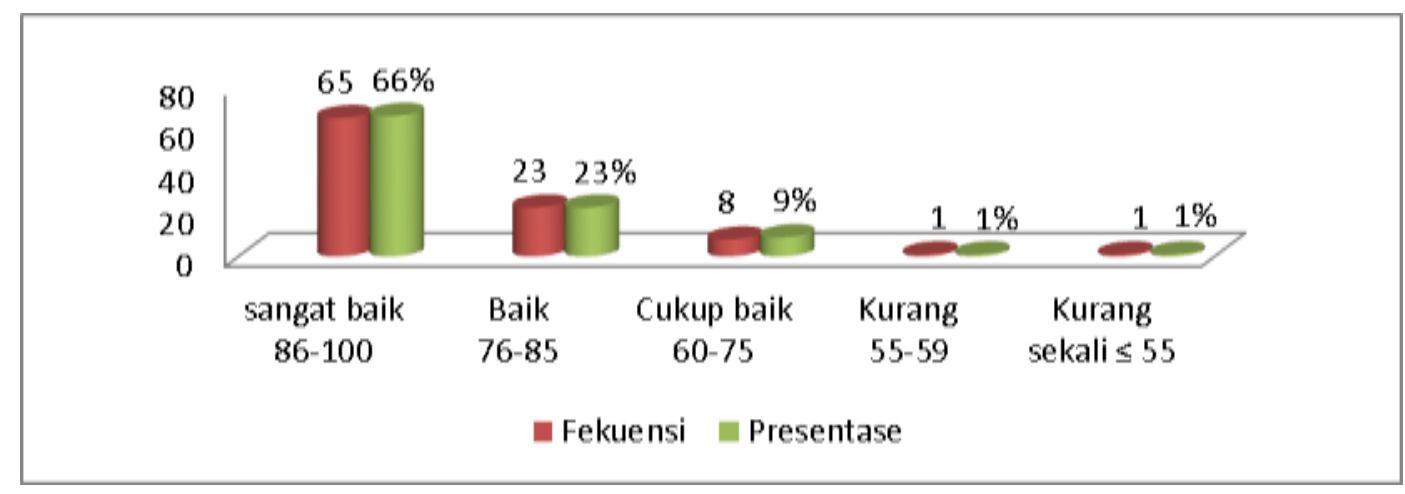

Gambar 1 Presepsi Siswa Terhadap Plakksanaan Shalat Dhuha

Berdasarkan diagram di atas menunjukan bahwa puncak kurva pelaksanan shalat dhuha berada pada kategori sangat baik dengan perolehan skor 86-100 diperoleh frekuensi sebanyak 65 orang dengan presentase $66 \%$. Kemudian, skor 76-85 diperoleh frekuensi sebanyak 23 orang dengan presentase $23 \%$ berada pada kategori baik, kemudian skor 60-75 diperoleh frekuensi sebanyak 8 orang dengan presentase 9\% berada pada kategori cukup baik, kemudian pada skor 55-59 diperoleh frekuensi sebanyak 1 orang dengan presentase $1 \%$ berada pada kategori kurang, dan skor $\leq 54$ diperoleh frekuensi sebanyak 1 orang dengan presentase $1 \%$ berada pada kategori kurang sekali. Sehingga dapat dikatakan bahwa sebagian besar siswa di MIN 1 Kendari melaksnakan shalat dhuha dengan sangat baik.

\section{Pembentukan Karakter Siswa di MIN Kendari}

Sekolah sebagai institusi yang sangat berperan penting untuk mengembangkan dan membentuk karakter siswa. Pendidikan adalah usaha meningkatkan diri dalam segala aspek. Pendidikan mempunyai pengaruh yang sangat besar karakter, akhlak, etika seseorang sehingga baik dan buruknya seseorang karakter seseorang sangat tergantung pada pendidikan. (Gunawan., 2014). Pembentukan karakter di MIN 1 Kendari pembentukan karakter dimulai dari sikapnya, tutur bahasanya, bahasa yang digunakan oleh siswa adalah bahasa pasar atau bahasa yang kasar karena kondisi sekolah berada dilingkungan pasar, oleh karena itu sekolah mengarahkan dan membiasakan siswa untuk berbahasa yang sopan, agar siswa setelah menyelesaiakan sekolahnya atau keluar dari lingkunagan sekolah bisa menciptakan atau bertutur kata yang baik dan sopan, dan kedisiplinannya, jika ada siswa yang terlambat kesekolah atau terlambat masuk kelas sekolah mempuyai atauran untuk siswa yang terlambat kesekpolah atau yang tidak disiplin maka akan berikan hukuman dengan membersihkan lingkunan sekolah. Bentuk hukuman yang diberikan kepada siswa seperti menyapu ruang kelas, memungut sampah dihalaman sekolah. Bentuk hukuman ini untuk merupakan pembinaan kepada siswa agar membentuk karakter siswa menjadi lebih baik serta memiliki kepedulian terhadap kedisiplinannya.

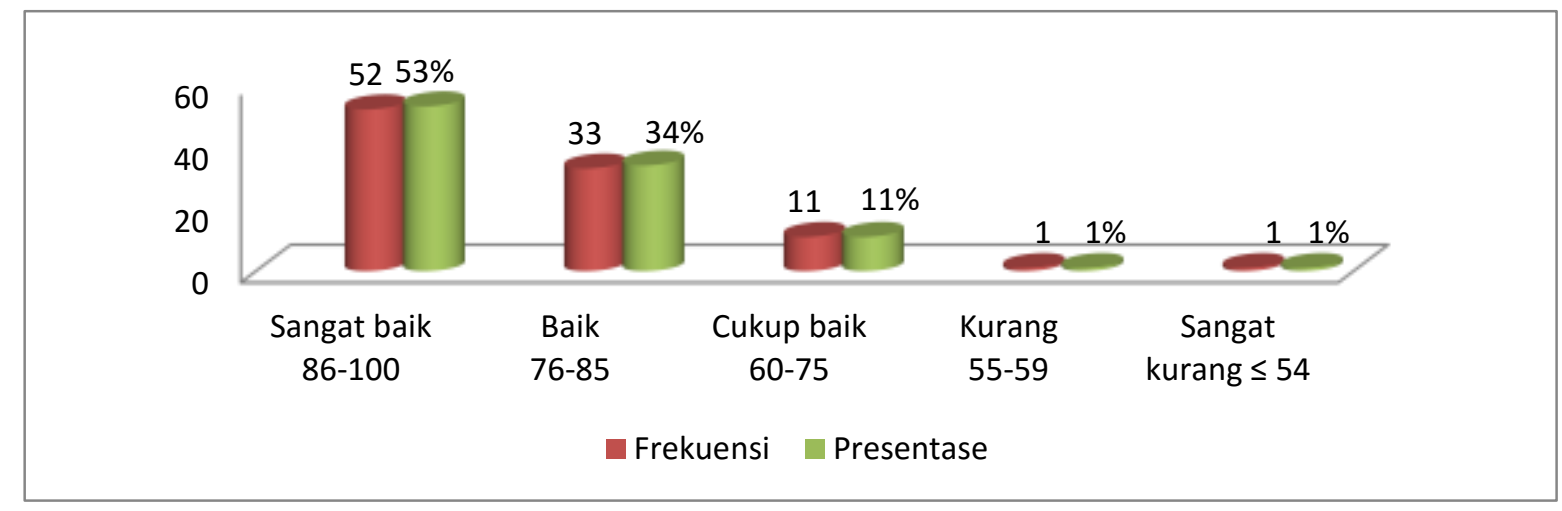

Gambar 2 Presepsi Siswa Terhadap Pembentukan Karakter 
Berdasarkan diagram di atas menunjukan bahwa puncak kurva pembentukan karakter siswa berada pada kategori sangat baik dengan perolehan skor 86-100 diperoleh frekuensi sebanyak 52 orang dengan presentase 53\%. Kemudian, skor 76-85 diperoleh frekuensi sebanyak 33 orang dengan presentase $34 \%$ berada pada kategori baik, kemudian skor 60-75 diperoleh frekuensi sebanyak 11 orang dengan presentase $11 \%$ berada pada kategori cukup baik, kemudian pada skor 55-59 diperoleh frekuensi sebanyak 1 orang dengan presentase $1 \%$ berada pada kategori kurang, dan skor $\leq 54$ diperoleh frekuensi sebanyak 1 orang dengan presentase $1 \%$ berada pada kategori kurang sekali. sehingga dapat dikatakan bahwa sebagian besar siswa di MIN 1 Kendari mempunyai karakter yang sangat baik. Hal ini dapat diperjelas melalui histogram berikut ini.

\section{Pengaruh Shalat Dhuha Terhadap Pembentukan Karakter siswa di MIN 1 Kendari}

Persamaan regresi linear tersebut nilai $\mathrm{Y}^{\prime}=17,25$ dapat diprediksikan memiliki nilai positif, bahwa pembentukan karakter siswa bernilai 17,25 koefisien regresi variabel X positif sebesar 0,52 artinya shalat dhuha mempengaruhi karakter siswa di MIN 1 Kendari dengan besarnya harga a dan $b$ mempengaruhi Y sebesar 17,25. Angka korelasi sebesar 0,55 berarti korelasi tersebut bertanda positif, artinya hipotesis kerja (Ha) yang menyatakan bahwa terdapat pengaruh positif shalat dhuha mempengaruhi karakter siswa di MIN 1 Kendari, artinya "diterima" dan memperoleh $\alpha(0,05) 5 \%$ dan $\mathrm{n}=98$ maka diperoleh nilai $r_{\text {tabel }}=0,1671$ dengan demikian $r_{\text {hitumg }}$ lebih besar dari $r_{\text {tabel }}$ atau 0,55 $>0,1671$. Untuk mengetahui interprestasi terhadap angka indeks product moment secara kasar atau sederhana terletak pada 0,40 - 0,59 yang berarti korelasi antara shalat dhuha dan pembentukan karakter siswa adalah terdapat korelasi cukup baik (Sugiyono., 2007). Pengujian KD (koefisien determinasi) digunakan untuk mengukur proposi untuk presentase sumbangan variabel independen (X) yang diteliti terhadap variabel dependen (Y) bahwa shalat dhuha memberi sumbangsi sebesar 30\% terhadap pembentukan karakter siswa di MIN 1 Kendari dan 70\% dipengaruhi faktor lain yang tidak diteliti Seperti di pengaruhi oleh kecerdasan spritual, kecerdasan emisional. Perhitungan $t_{\text {hitung }} \alpha=$ $0.05(5 \%)$ dan $\mathrm{n}=98$ uji satu pihak, $\mathrm{dk}=\mathrm{n}-2,=98-2=96$ sehingga memperoleh $\mathrm{t}_{\text {tabel }}=1,66055$, ternyata $t_{\text {hitumg }}$ lebih besar dari $t_{\text {tabel }}$ atau $6,44 \geq 1,66055$ ), maka Ho ditolok, artinya terdapat pengaruh yang signifikan antara shalat dhuha terhadap pembentukan karakter siswa di MIN 1 Kendari.

\section{PEMBAHASAAN}

Berdasarkan hasil analisis data menunjukan bahwa terdapat pengaruh antara variabel $\mathrm{X}$ (pelaksanaan shalat dhuha) terhadap variabel $\mathrm{Y}$ (pembentukan karakter siswa), hal ini dapat dilihat dari hasil uji $\mathrm{t}$ dimana berdasarkan $r_{\text {hitumg }}$ lebih besar dari pada $r_{\text {tabel }}(0,55 \geq 0,1671)$ dan uji $t$ signifikansi $t_{\text {hitung }}$ $\geq t_{\text {tabel }}(6,44 \geq 1,66055$ adanya pengaruh shalat dhuha terhadap pembentukan karakter siswa dan hasil pengujian persamaan regresi yang diperoleh dapat diketahui bahwa shalat dhuha berpengaruh terhadap pembentukan karakter siswa dan didapatkan persamaan $\mathrm{Y}=17,25$

Shalat dapat mempengaruhi aspek psikologis yakni dapat mempengauhi kepribadian seseorang, termasuk Shalat dhuha karena shalat dhuha adalah ibadah yang menjadikan peantaran untuk mengubah pengalaman hidup menjadi lebih baik dengan melaksanakan shalat dhuha secara istiqomah.( Marufie., 2009). Shalat dhuha adalah shalat sunnah yang dilakukan saat matahari sudah naik kira-kira sepenggalah, atau kira-kira 7 hasta dan berakhir disaat matahari lingsir, akan tetapi disunahkannya melaksanakan di waktu yang agak akhir yaitu di saat matahari agak tinggi dan panas (Badrus., 2015). Disamping itu, hasil penelitian ini diperkuat dengan temuan penelitian yang dilakukuan Asmaul Husni. Menemukan bahwa shalat dhuha berpengaruh positif dan signifikan terhadap pembentukan karakter. (Husni.,2011). Menurut ibu Sumarni mengemukakan bahwa shalat dhuha mempunyai pengaruh terhadap pembentukan karakter siswa di MIN 1 Kendari, pengaruhnya yaitu kedisiplinan siswa, semenjak diadakan pelaksanaan shalat dhuha kedisiplinan siswa semakin baik $80 \%$ siswa tidak terlambat lagi ke sekolah, dari segi hafalan surah-surah pendek dan bacaan 
shalat dhuhanya sudah semakin baik dll. (Sumarni., 2019) Karakter adalah, "sebuah usah untuk mendidik anak-anak agar dapat mengambil keputusan denga)

Berdasarkan nilai kedua variabel memiliki pengaruh dalam kategori yang sedang, karena berdasarkan perhitungan rumus product moment kedua variabel memiliki koefisien korelasi 0,55. Artinya shalat dhuha harus ditingkatkan lagi sehingga pembentukan karakter siswa meningkat. Kemudian, untuk mengetahui besar sumbangsi shalat dhuha terhadap pembentukan karakter siswa, dihitung menggunakan rumus koefisien deteriminasi (KD) diperoleh hasil sebesar 30\%. Berdasarkan hal tersebut diketahui bahwa besarnya peningkatan maksimal pada pembentukan karakter merupakan hasil dari pelaksanaan shalat dhuha sebesar 30\% sedangkan 70\% adalah diberikan oleh faktor lain yang tidak diteliti. Seperti dipengaruhi oleh kecerdasan spritual, kecerdasan emosional. n bijak dan mempraktikannya dalam kehidupan sehari-hari, sehingga mereka dapat memberikan kontribusi yang positif kepada lingkungannya (Kesuma, 2011). Gerakan pendidikan dibawah tanggung jawab suatu pendidikan untuk memperkuat karakter peserta didik melalui harmonisasi, olah hati, olah rasa, olah pikir dan olah raga dengan pelibatan dan kerja sama antara satuan pendidikan, keluarga, dan masyatakat sebagai bagian dari gerakan nasional revolusi mental (GNRM) (Zarkasi., 2018)

\section{SIMPULAN}

Dari hasil analisi data dan pembahasan menunjukan bahwa pelaksanaan shalat dhuha terhadap pembentukan karakter siswa di MIN 1 Kendari terdapat pengaruh positif dan signifikansi shalat dhuha terhadap pembentukan karakter siswa dengan $r_{\text {hitumg }}$ lebih besar dari pada $r_{\text {tab } \theta l}(0.55 \geq 0.1671)$

dan uji $t$ signifikansi $t_{\text {hitung }} \geq t_{\text {tabel }}(6,44 \geq 1,66055)$ maka $H_{I}$ diterima dan $H_{0}$ ditolak artinya terdapat pengaruh yang positif dan signifikan shalat dhuha terhadap pembentukan karakter siswa di MIN 1 Kendari dengan demikin hipotesis awal yang menyatakan bahwa pengaruh shalat dhuha terhadap pembentukan karakter siswa dapat diterima. Hasil analisis koefisien deteriminasi (KD) pengaruh shalat dhuha terhadap pembentukan karakter siswa sebesar 30\%. Pelaksanan shalat dhuha di MIN 1 kendari dilakuka pada hari jumat pagi sebelum pembelajaran dimulai dan peroleh hasil fekuensi 65 dari skor perolehan 86-100, sehingga dapat dikatakan bahwa sebagian besar siswa melaksanakan shalat dhuha berada pada kategori sangat baik dan Pembentukan karakter siswa di MIN 1 Kendari dimulai dari tutur bahasanya, kedisiplinan dan kejujuran siswa, dan peroleh hasil fekuensi 52 dari skor perolehan 86-100, sehingga dapat dikatakan bahwa karakter siswa di MIN 1 Kendari termasuk dalam kategori sangat baik.

\section{DAFTAR PUSTAKA}

Al-Tirmidzi Isa bin Abu Isa Muhammad. (2000). Sunan al-Tirmidziy, jilid II (Bairut: Dar al-Garbi alIslamiy. 320

Aziz Muslim Muhammad. (2008). Mutiara,itu Bernama Shalat Sunah, Surabaya: PT Mizan Publika. 54

Fil Amorulah, Bahar Muhammad. (2008). Panduan Lengkap Shalat Sunnah Surakarta: Indiva Pustaka.32

Husni, Asmaul. (2011) Pengaruh Shalat Dhuha Terhadap Pembentukan Karakter Siswa di MAN Tlogo Blitar. Jurnal Pendidikan Vol 4.7

Margono. (2010). Metodelogi Penelitian Pendidikan, Jakarta:Rineka Cipta.55

Marufie Al Sabil. (2009). Dasyatnya Shalat Dhuha Pembuka Pintu Rezeki, Bandung:Mirzan Pusataka. 22

Siswanto dan Suyanto. (2017). Metodelogi Penelitian Kuantitatif Korelasional, (Jakarta: PT Rineka Cipta.75

Sugiyono. (2008). Metode Penelitian Pendidikan, Bandung: CV. Alvabeta.54

Taqiudin Zarkasi \& Al Kusaeri. (2018). Penguatan Pendidikan Karakter di Madrasah. Jurnal AlMuta'aliyah Vol 3.5

Undang-Undang RI.No 20 Tahun 2003. Tentang Sistem Pendidikan Nasional. Direktur Jendral Pendidikan Islam Departemen Agama RI, Jakarta: 2006. 6 
Wahyono, Nuryadi. (2017). Hubungan Shalat Dhuha Dengan Kecerdasan Emisional Siswa Kelas X Di SMA Muhamadiyah 7 Surabaya. Tadarus Jurnal Pendidkan Islam. Vol 6. 2

Wibowo, Agus. (2013). Manajemen Pendidikan Pendidikan Karakter, Yogyakarta: Pustaka Pelajar. 40

Zaman, Badrus. (2015). Pembinaan Kaakter Siswa Melalui Shalat Sunah Dhuha Di Sekolah Dasar. Jurnal Pendidkan: Vol 1.2 